Please do not remove this page

RMIT

UNIVERSITY

\title{
Occupational health, safety and workers' wellbeing
}

Lingard, Helen

https://researchrepository.rmit.edu.au/esploro/outputs/9921858695501341/filesAndLinks?institution=61RMIT_INST\&index=null

Lingard, H. (2012). Occupational health, safety and workers' wellbeing. In Human Resource Management in Construction: Critical Perspectives (pp. 130-162). Routledge.

https://researchrepository.rmit.edu.au/discovery/fulldisplay/alma9921858695501341/61RMIT_INST:Resea rchRepository

Document Version: Published Version

Repository homepage: https://researchrepository.rmit.edu.au

(c) 2012 Routledge

Downloaded On 2023/04/26 16:41:20 +1000

Please do not remove this page 
Thank you for downloading this document from the RMIT Research Repository.

The RMIT Research Repository is an open access database showcasing the research outputs of RMIT University researchers.

RMIT Research Repository: http://researchbank.rmit.edu.au/

\section{Citation:}

Lingard, H 2012, 'Occupational health, safety and workers' wellbeing' in Andrew Dainty and Martin Loosemore (ed.) Human Resource Management in Construction: Critical

Perspectives, Routledge, United States, pp. 130-162.

See this record in the RMIT Research Repository at:

http://researchbank.rmit.edu.au/view/rmit:16797

Version: Published Version

Copyright Statement: (c) 2012 Routledge

Link to Published Version:

http://trove.nla.gov.au/version/183677906

\section{PLEASE DO NOT REMOVE THIS PAGE}




\title{
6 Occupational health, safety and workers' wellbeing
}

\author{
Helen Lingard
}

\section{Introduction}

Occupational health and safety (OHS) is often regarded as something that must be 'implemented' within organisations. The production of documents, including safety policies, procedures and plans, is often misconstrued as 'doing safety' in organisational life. It is believed that, by following the principles and practices embodied in established OHS management systems, workplace hazards will be controlled to within acceptable levels of risk. Indeed, there are many companies, even in the high risk construction industry context, that perform very well in OHS. However, the attainment of OHS is the result of more than implementing an OHS management system. OHS is the outcome of organising work properly and holding persons with OHS responsibility accountable for their actions. It is very common that organisations in which third party accredited OHS management systems have been implemented continue to demonstrate considerable 'patchiness' in OHS performance, reflecting project-by-project variation in the degree of local effort that is made to deliver OHS outcomes. It is important to recognise that the implementation of an OHS management system will only make a difference if it is accompanied by genuine commitment, will and effort to improve OHS. It is also essential that OHS is integrated into business and project decision-making. OHS should be a primary responsibility of managers at all levels within organisations, from Chief Executive Officers to first-level supervisors, foremen and team leaders. Regarding OHS as a separate management function decouples it from the 'main game' - the operational management of a construction organisation or project. If this connection is not clear, the activities of OHS advisors can appear irrelevant, uncoordinated and even counter-productive, and the performance of an OHS management system will not meet expectations (Gallagher, Underhill and Rimmer, 2003).

Occupational health, safety and workers' well being is a central component of the ethical and responsible management of people. The human impacts of occupational injury and illness include impaired domestic and daily function, strained family relationships, negative psychological and behavioural 
responses, stress and loss of vocational function. Although they are difficult to quantify, these impacts are considerable and substantially increase the demand for social and health services. In the construction industry, occupational injuries and illnesses are associated with longer than average work absences (Larsson and Field, 2002) and higher rates of permanent impairment than in other sectors (Guberan and Usel 1998). Health is an important resource, contributing to the economic and social wellbeing of workers and their families and responsible and proper management of workers' health, safety and wellbeing is essential to ensuring that construction workers achieve healthy, productive life outcomes.

This chapter deliberately does not focus upon the components of OHS management systems, which are amply described elsewhere. Instead, the chapter addresses some important points of ongoing debate in construction OHS research and practice. First, the chapter examines the argument that there is a natural identity of interest between workers and employers with regard to OHS because workplace injuries are costly to organisations. The role and structure of frameworks regulating OHS are described. Labour market characteristics increasing the vulnerability of construction workers to workplace injury and illness are then explored. Contemporary theories pertaining to antecedents of workplace incidents are briefly described with their implications for attributing professional responsibility for OHS within the construction supply chain. The impact of emergent causes of workrelated injury and illness, including long hours, fatigue and work stressors, is also considered in the construction context. The shift in emphasis from efforts to prevent work injury and illness to the positive promotion of workers' health and well being is described and a case study is used to illustrate health promotion interventions implemented at one prominent construction project in Melbourne, Australia. Key organisational issues of managerial accountability, safety culture and leadership are discussed. A second case study highlights the role played by managers' conduct in shaping the local safety climate and injury performance of construction work crews. Key issues of worker involvement in organisational safety processes and trust are also considered in the construction context. The chapter concludes with a discussion of the importance of promoting a healthy and productive workforce for the sector.

\section{Relationship between safety and profitability: myth or reality?}

In recent decades, it has become very popular for OHS writers and practitioners to base the OHS case on the cost savings to be made from reducing the incidence of events resulting in death, injury or illness. Unfortunately the 'business case' arguments for OHS have tended to overshadow discussion of the moral imperative to provide a healthy and safe workplace. This is problematic because in most instances the provision of a safe and healthy work environment requires investment incurring a monetary 


\section{Helen Lingard}

cost to organisations. An economic rationalist approach would suggest that when this cost exceeds the monetary savings that will be gained from a subsequent reduction in work-related injuries or illnesses, no further investment should be made. As described below, there are substantial problems inherent in this argument. Indeed, it is unlikely that the economically optimal level of investment in the prevention of work-related injury and illness for a single organisation will produce a socially (or morally) acceptable level of OHS risk. Indeed, the notion of what constitutes an 'acceptable' level of OHS risk cannot be understood in terms of a simple cost-benefit analysis undertaken by management. Rather, it must be considered as part of an ongoing and inclusive discussion between workers (and their representative unions), employers and governments.

It is simplistically argued by many OHS writers that the costs of OHS incidents are so great that existing economic incentives can motivate organisations to invest in safe and healthy technologies and work systems. These arguments are often based upon national or aggregated figures. The costs of workplace injury are indeed substantial. For example, in Australia, the National Occupational Health and Safety Commission (2004) estimated that the cost of workplace injuries to the Australian economy for the 2001-02 financial year was $\$ 31$ billion. In the UK, the Health and Safety Executive quantified the costs of safety incidents in a number of British industries, including construction. The study found, on an annual basis, the costs of incidents was 8.5 per cent of the price of tendered work in the construction organisation (Cutler and James, 1996).

However, drawing conclusions about enterprise-level incentives to reduce the incidence of workplace injury from these aggregate figures is problematic. As Hopkins (1999) points out, what matters is not how much injuries cost, but who bears the cost of these injuries. The most relevant question is not how much injuries cost the economy but how do the costs borne by employers (who are in the best position to control workplace hazards/risks) compare with the costs of prevention?'

An Australian Industry Commission study (1995) reports that employers incur only 30 per cent of the total costs of workplace injury, with the remaining costs borne by workers and the community. Furthermore, the proportion of costs borne by the employer reduces with the severity of an injury. Thus, the Industry Commission concludes that financial incentives for employers to prevent injuries are 'inadequate, particularly for serious incidents' (Industry Commission, 1995, p. 102). More recent analysis reveals that the proportion of injury costs borne by employers may even be as low as three per cent of total costs, with 44 per cent borne by workers and 53 per cent borne by the community (NOHSC, 2004).

Even when costs are considered at the level of a single enterprise, Hopkins (1999) points out that it is insufficient to base the argument that 'safety pays' on the magnitude of the costs of incidents. A rational calculation needs to be based on a reliable quantification of the costs of incidents and the costs 
that would be incurred trying to prevent these incidents. Hopkins (1999) suggests that, in the case of high frequency injuries, cost-benefit assessment may motivate rational employers to invest in prevention, while this may not be the case for the prevention of low probability catastrophic events. Consequently, he cautions against making the assumption that it will always make sense for employers to invest in OHS.

Organisations need to be more cognisant of the problems inherent in reliance on cost-benefit arguments for investment in OHS. In this context, investment decisions should be based upon more robust processes involving the involvement of workers, whose OHS will be impacted by decisions that are made.

\section{OHS regulation}

If it is accepted that the natural economic incentive for organisations to invest in OHS may be insufficient to produce 'acceptable' levels of performance, alternative drivers must be considered. One important driver exists in government intervention in the regulation of OHS.

The way organisations treat their workers is an issue that raises ethical concerns (Greenwood, 2002). Rowan (2000) suggests three ethical principles for the management of people, based upon an individuals' right to pursue their own interests. These are: the right to freedom; the right to wellbeing; and the right to equality. Workers have a moral right to be treated fairly and to be provided with a healthy and safe work environment and work conditions that will not harm their general physical or psychological wellbeing. Logically, it is employers who have a concomitant duty to provide a suitably healthy, safe and hazard-free work environment for workers. In recognition of these rights, modern societies have passed legislation to protect workers' health and safety in and arising from work. However, this OHS legislation can take different forms. In many Western countries, a selfregulatory approach has been adopted. The ability of this approach to, deliver high standards of OHS has been questioned by some writers (see, e.g., Dawson, Willman Clinton and Bamford, 1988).

Since the 1970s in the United Kingdom (and the early 1980s in Australia) OHS legislation has moved away from a detailed prescriptive model, in which technical solutions to specific hazards were prescribed in detailed specification standards. In these countries, legislation has shifted to a more 'flexible' approach, in which dutyholders are able to decide, for themselves, how to comply with broad-based general duties. This move followed recommendations made by the Robens Committee of Enquiry in the United Kingdom, which argued that dutyholders had difficulty in identifying what their legal obligations were due to the large volume of OHS legislation that had been adopted on a piecemeal basis since the industrial revolution. Although the law was vast and complex, the 'ad hoc' nature of enactment gave rise to gaps in coverage. Additionally detailed laws prescribing technical 
solutions to OHS hazards were cumbersome, could not keep pace with technological change and prevented dutyholders from finding new and innovative ways to improve OHS. The Robens-inspired legislative reform moved from a specification-standards approach to a more self-regulatory model, based upon employer and employee consultation and workplace decision-making.

The Robens model includes two principal elements: (i) a single umbrella statute containing broad 'general duties' based on the common law duty of care; and (ii) the empowerment of dutyholders, in consultation with employees, to determine how they will comply with those general duties' provisions. The general duties provisions establish a requirement for dutyholders to provide a healthy and safe workplace, but do not indicate to dutyholders bow to comply, i.e. they are principle-based, rather than prescriptive. The practical method of compliance with this type of legislation is to be determined by dutyholders. Moreover, the general duties are not absolute and are limited by words like 'so far as is practicable' or 'reasonably practicable.'

In some jurisdictions, this legislative approach establishes a three-tiered 'hierarchy' in which the general duties contained in the 'umbrella' Act are supplemented by process-based regulations and hazard-based (nonmandatory) codes. Process-based standards go further than establishing general duties and focus attention on how OHS is to be managed. They require dutyholders to follow a certain process, or series of steps in the identification, assessment and control of workplace hazards. Non-mandatory codes of practice provide a greater level of detail to dutyholders about ways in which they can comply with their general duties in relation to specific hazards, e.g. working at height and manual handling. Though not mandatory, codes assist dutyholders by suggesting how they are able to comply with the legislation on a particular issue. Codes of practice possess quasi-legal status, as measures described in a code are deemed to comply with the legislation (Bluff and Gunningham, 2003).

In contrast to the UK/Australian legislative model, some countries have retained a large volume of prescriptive OHS law. For example, in the USA, the Occupational Safety and Health Act (OSHA), is the primary federal law governing OHS. Section 5 of OSHA contains a general duty clause requiring employers to: (i) maintain conditions or adopt practices reasonably necessary and appropriate to protect workers on the job; (ii) be familiar with and comply with standards applicable to their establishments; and (iii) ensure that employees have and use personal protective equipment when required for safety and health. However, OSHA also contains a great deal of detailed prescriptive specification standards establishing requirements for the control of mechanical and chemical hazards. International comparative figures produced by the International Labour Organization suggest that the OHS performance of the US construction industry is notably poorer than that of the UK and/or Australia. For example, the ILO LABORSTA database reports a fatality rate of 4.4 per 100,000 workers for the construction industry 
in Australia in 2008, compared with a rate of 10.0 for the USA in the same year. The latest figures available in the LABORSTA database for the UK relate to 2006 , when the fatality rate for construction was 4.5 per 100,000 workers. However, it is not possible to attribute these differences to the legislative framework as there are many other differences (e.g. in the prevailing economic framework and industrial climate), that are likely to be relevant.

\section{Vulnerable workers}

One assumption underpinning the Robens Committee's thinking was that there is a 'natural identity' of interest between employers and workers in relation to OHS. Nichols (1997) argues that this premise cannot be uncritically accepted. If a 'natural identity' exists then Nichols (1997) questions why levels of workplace injury are so persistent as the only explanation can be that workers and/or employers consistently act irrationally in failing to pursue their own interests. As the above discussion of the costs of injury, illness and death reveals, it is dangerous to assume that employers acting rationally will invest in prevention. Indeed, Nichols (1997) argues that OHS must be understood in relation to the larger economic system in which workers and employers operate. In this system, workers' unsafe acts are sometimes a 'rational' response to production pressures. The self-regulatory focus of Robens thinking, in which employers and workers would work together to find solutions to OHS problems through a process of consultation at the workplace may actually be misguided. Workers' ability to influence OHS standards in the workplace is likely to be impeded by the power imbalance inherent in the employment relationship. Further, the ability to engage in meaningful consultation with employers in relation to OHS is likely to be particularly difficult among vulnerable worker groups, which make up a reasonable proportion of the construction industry. What follows is a brief discussion of three groups of vulnerable workers whose labour construction organisations are increasingly reliant upon, namely young workers, migrant workers and workers engaged in casual or precarious employment.

\section{Young workers}

The Australian construction industry has a relatively young age profile. For example, Australian Bureau of Statistics data indicates that 62.6 per cent of construction workers are under the age of 45 compared to 59.6 per cent of workers in all industries. The percentage of construction workers 45 years or over was 37.4 per cent in construction compared to 39.8 per cent in all other industries (Government of South Australia, 2009). Notwithstanding this age profile, the physical nature of some trade sectors of construction work can result in an earlier age transition from trades to other roles within the construction industry, which impacts upon the supply of labour in these 


\section{Helen Lingard}

trades. It is therefore imperative that the work health, safety and wellbeing of younger construction workers is carefully managed.

The work injury rates of young workers, aged 15-19 are reported to be significantly higher than those of older adults in European and US research (Salminen, 2004; Breslin and Smith, 2005). For example, in a study of fatal incidents in the US construction industry involving contact with electricity, Janicak (2008) reports a significantly higher proportion of fatalities in the 16 to 19 year age group. This group had an actual Proportionate Mortality Ratio (PMR) of 20, compared to an expected PMR of 13.8. Lavack, Magnuson, Deshpande, Basil, Basil and Mintz (2008) report that 50 per cent of accidents involving young workers occur during the first six months in a job.

In Australia, the rate of work-related death among workers aged between 15 and 19 was 3.4 per 1,000 between 1989 and 1992 . The majority of the 106 work-related deaths to young workers occurring in this period involved labourers, tradespersons (many of whom are apprentices) and machinery operators, i.e., occupations commonly found in the construction industry (Driscoll, 2006). Further, construction was one of the main industries in which young Australian workers were killed (with agriculture, manufacturing and trade). Indeed, construction accounts for 19 per cent of the work-related deaths of workers under 19 years of age, but only 13 per cent of all workrelated deaths, which is indicative of the vulnerability of young construction workers.

Reasons for the prevalence of work injury among young workers are complex and include personal factors, such as inexperience, levels of emotional and physical maturity and cognitive functioning. However, young workers are often employed in low paid or part-time jobs on a temporary, casual or informal basis. They may not know their legal rights, or be lacking in the self-confidence, communication or social skills to express safety concerns (Loughlin and Frone, 2004). Chin, DeLuca, Poth, Chadwick, Hutchinson and Munby (2010) suggest that, in Canada, although OHS training is a legal requirement, up to 50 per cent of young workers do not receive any OHS training. Further, the training that is provided is typically informational, providing young workers with knowledge of OHS hazards. Rarely is OHS training for young workers 'instructional' in the sense that it provides young workers with a deeper understanding of the reasons for unsafe conditions in the workplace and/or skills they need to address the social risk associated with making a safety complaint in their workplace (Chin et al., 2010).

Even if they understand their legal rights, young workers may be eager to earn the approval of their supervisors. Tucker, Chmiel, Turner, Hershcovis and Stride (2008) report that young workers are less willing or able to engage in communication aimed at improving workplace safety (a term they refer to as employees' 'safety voice') than older workers. The researchers surmise that this may be due to a desire to appear hardworking and able to 
carry out allocated work tasks. The reluctance to voice safety complaints or concerns is particularly prevalent among male workers in industries including construction (Breslin, Polzer, MacEachen, Morrongiello and Shannon, 2007). In particular, young male workers are reported to accept workplace injury as 'part of the job' about which there is no point complaining. Breslin et al. (2007) suggest that this attitude is fundamentally linked to the endemic industry culture and prevailing power imbalance that exists in many workplaces, particularly when young workers are employed on a casual, informal or temporary basis. In this context, young workers have little control over their work environment and their subordinate position leads them to accept unsafe conditions and even injuries.

\section{Migrant workers}

Globalisation has seen an increasing use of migrant workers in the construction industries of many countries. In the USA, the number of Hispanic workers in the construction industry has tripled over a ten-year period to reach three million in 2006, almost a quarter of the industry (Dong, Fujimoto, Ringen and Men, 2008). In one UK study by Bust, Gibb and Pink (2008), the average proportion of migrant workers employed by contracting organisations was ten per cent but one contractor indicated migrant workers made up 40 per cent of the workforce. In Australia, NonEnglish-Speaking Background (NESB) migrants account for approximately 12.5 per cent of the nation's 800,000 construction workers (Trajkovski and Loosemore, 2006). The increasing reliance on foreign construction workers presents significant challenges for the management of OHS. Research suggests that migrant workers in many countries are at a higher risk of workplace death, injury and illness than domestic construction workers. For example, Dong et al. (2008) report that between 1992 and 2006, Hispanic workers in the USA consistently experience a higher rate of fatal falls than non-Hispanic workers. Further, during this period, the death rate of Hispanic workers increased while it remained the same for non-Hispanic workers. Although Hispanic workers were 1.5 times more likely to die in a fall than non-Hispanic workers, the rate of falls was particularly high among Hispanic workers born outside the USA (5.5 compared to 3.8 per 100,000 FTE for all construction workers and 4.1 per 100,000 FTE for Hispanic workers born in the USA). In Australia, Trajkovski and Loosemore (2006) cite Australian Bureau of Statistics data showing injuries to foreign-born workers make up 29 per cent of documented workplace grievances. Many of these injuries involved tradesmen or labourers.

One of the most immediate challenges associated with managing a culturally diverse workforce is the need to communicate OHS information in a manner in which it can be understood and acted upon (Bust $e t$ al. 2008). Trajkovski and Loosemore (2006) suggest that, in Australia, the English language proficiency of many foreign construction workers has not been 


\section{Helen Lingard}

adequately addressed in the design and delivery of mandatory OHS training programmes. Further, site-based communication of safety requirements and instructions is rarely communicated in a language other than English. Bust et al. (2008), advocate the use of symbols, photographs and videos to communicate OHS messages, but point out that it is essential to evaluate how OHS messages are received and understood by workers of different ethnicities and/or cultures. Another important aspect of addressing the OHS challenge presented by migrant workers is in finding ways to secure the participation of those workers in OHS management processes. Haslam et al. (2005) identify worker participation in managing OHS as important in the identification of solutions to workplace OHS problems. There is evidence that migrant workers are less likely to engage in employer-employee consultation concerning OHS due to their often limited formal education, language difficulties, position of economic need and low level of knowledge about OHS legislation (Williams, Ochsner, Marshall, Kimmel and Martino, 2010). Williams et al. (2010) describe a peer-led participatory OHS training programme that was developed and trialled among Hispanic workers in the US construction industry. The training programme was implemented in partnership with unions and community groups and was designed to increase OHS knowledge and capability by providing group training to 'day labourers', a particularly vulnerable group of workers in the USA. A series of focus groups were initially conducted with representatives of the target population to identify typical exposures and work situations. Training activities were developed based upon principles of 'active learning' and training in topics, such as falls prevention and legal rights, was delivered through 'peer trainers.' Williams et al. (2010) report increased OHS knowledge among participants following the training, as well as an increased willingness among participants to communicate OHS information to their co-workers and advocate workplace safety.

\section{Casual (and often precarious) employment}

In developed countries, there has been a shift away from permanent fulltime employment to an increasing reliance upon temporary, part-time, subcontracting, labour hire and own-account self-employment (Fabiano, Currò, Reverberi and Pastorino, 2008). Research suggests that job insecurity associated with precarious forms of employment can have a deleterious effect on workers' physical and psychological health and wellbeing (Quinlan, 2007; Emberland and Rundmo, 2010). In an analysis of Italian OHS data, Fabiano et al. (2008) point out that the frequency index of workplace accidents is 2.55 times higher for temporary workers in all industries than it is for the highest risk sector at a national level (which was the building industry). They conclude that temporary work may be considered a risk factor for workplace accidents and suggest that this may be explained by levels of industry or organisation-specific experience 
and/or knowledge, insufficient training, a high workload and work pressure. Similarly, in Spain, Guadalupe (2003) demonstrates that workers engaged in fixed-term contracts have a significantly higher probability of having an accident in the workplace than workers on permanent contracts.

Subcontracting is a key feature of the construction industry, which is known to present significant challenges in the management of OHS (Arditi and Chothibongs, 2005; Loosemore and Andonakis 2007). Australian research by Mayhew, Quinlan and Ferris (1997) reveals that the 'paymentby-results' system under which most subcontract work is undertaken pushes contractors to work excessive hours and 'cut corners' with respect to OHS. Further, organisational complexity and ambiguity about OHS responsibility, associated with 'pyramid' subcontracting, inadequate regulatory controls and the low levels of union representation among the self-employed (also discussed in Chapter 10) increase the level of OHS risk experienced by subcontracted/self-employed workers. Another worrying aspect of the prevalence of 'own account' self-employed workers in the Australian construction industry is that injuries to these workers are not reflected in national compensation-based OHS statistics. Mayhew et al. (1997) point out that compensation data are used to inform preventive strategies so the absence of injuries to these workers from compensation statistics means that self-employed subcontractors are seldom the focus of prevention efforts. Because they are ineligible for workers' compensation, financial pressures can result in self-employed workers not seeking proper treatment and/or continuing to work while injured, increasing their risk of developing longterm, chronic conditions.

In the construction industry it is evident that age, work inexperience, contingent work arrangements and ethnicity interact in complex ways to render specific groups at considerable risk of work-related harm. In addressing the OHS challenges it faces, the construction industry must carefully consider how vulnerable worker groups are socialised into industry practice to ensure that poor OHS standards and work injury are not regarded as the 'norm.' Efforts to educate vulnerable worker groups about OHS risks and their rights under OHS legislation are critical in order to provide the knowledge-base for these workers to advocate for their own and others' OHS. However, as Breslin et al. (2007) note, placing responsibility primarily on vulnerable worker groups to look after their own OHS is insufficient because imbalanced power relationships in many workplaces are likely to discourage workers from making safety complaints. This problem will be compounded for vulnerable workers. It is therefore important that organisational human resource management policies and procedures are designed to redress these inherent power imbalances and actively engage all workers in making decisions about OHS in the workplace. The provision of specific OHS training to vulnerable worker groups, the implementation of culturally appropriate orientation programmes for migrant workers and/or 
special initiatives to mentor young workers are possible strategies to be considered, within the broader HRM functions of workforce recruitment, development and management.

\section{Nature and antecedents of injury}

\section{Injury/incident causation}

Injuries and incidents can be explained in different ways depending upon the causation model that is used to analyse them. Different models of injury/ incident causation emphasise different aspects and are likely to give rise to different recommendations for prevention (Katsakiori, Sakellaropoulos and Manatakis, 2009). Lundberg, Rollenhagen and Hollnagel (2009) refer to this phenomenon as 'What-You-Look-For-Is-What-You-Find' and suggest the corollary of this is 'What-You-Find-Is-What-You-Fix.' It is therefore very important to comprehend the assumptions embedded in different theories about how factors interact to cause injuries/incidents.

Early models of injury/incident causation were simple linear 'cause-effect' models that described an incident as a sequence of events that occurred in a specific order, such as the 'domino model' (Heinrich, 1959). An injury was seen as the logical conclusion of a sequence of events that commenced with a person's ancestry and social environment. This was a precursor to personal factors which, in turn, contributed to the existence of unsafe acts and/or conditions. Unsafe acts and conditions were the immediate precursors of accidents, which gave rise to injury. Heinrich's model has been criticised for focusing too much attention on the injured worker and the immediate circumstances surrounding accidents.

More recent models of injury/incident causation have recognised that injury/incident causation is more complex than the early linear sequential models would suggest. In fact systemic causative factors that may be present in organisations for many months or even years without the occurrence of an incident are now understood to be important antecedents to injury (Lundberg et al., 2009). So-called 'systemic' causation models highlight organisational and cultural factors in creating the conditions in which a precipitating event can result in a major incident. James Reason's 'Swiss cheese' model is the most widely cited model of this type. According to Reason (1990), incidents are caused by a complex interaction of latent and active failures. Active failures are immediate observable causes, similar to Heinrich's unsafe acts or conditions. These can be easily identified. However, latent failures may also be present in work systems. In a sense these are 'accidents waiting to happen.' These can include poor design, low levels of training, a mismatch between levels of competence and responsibility and other systemic deficiencies. Over time, work systems build up defences against these latent failures. In local workplaces, latent conditions combine with natural human tendencies and result in human errors or violations. 
These are unsafe acts committed at the human-system interface. Reason suggests that many unsafe acts occur, but very few of them result in losses because systems have in-built defences, likened to layers of Swiss cheese. But, like Swiss cheese, these barriers have holes in them which vary in size over time. Should a situation arise in which the holes 'line up', the system's defences fail and errors result in organisational accidents. Systemic models of injury/incident causation permit an analysis of causal factors that are chronologically, geographically or organisationally removed from the worksite. Thus, the focus is not solely on the immediate circumstances surrounding the incident. In the construction context, this means that the cause of injuries/incidents may be traced back to systemic failures in the way that construction projects are procured, organised and managed (Suraji, Duff and Peckitt, 2001; Manu, Ankrah, Proverbs and Suresh, 2010). An implication of adopting this systemic approach is that the investigation of workplace injuries/incidents in construction should examine the contribution of all parties, beginning with the injured worker, through supervisors, site managers, construction planners, construction company senior managers, designers, project managers and even clients.

A report prepared by Loughborough University and UMIST on behalf of the UK's Health and Safety Executive sought to test a systemic model of OHS incident causation by carefully investigating the causes of 100 construction incidents. The research team used the information obtained from people involved in selected incidents, including the victims and their supervisors, to describe the processes of incident causation in construction (HSE, 2003). The HSE model identifies originating influences affecting incidents in construction as including client requirements: features of the economic climate; the prevailing level of construction education; design of permanent works; project management issues; construction processes; and the prevailing safety culture and risk management approach. In particular, the analysis of the 100 incidents revealed that, in half of the cases, the risk of accidental injury could have been reduced with a change to the permanent design of the facility being constructed. Deficiencies in the risk management system were also apparent in almost all of the 100 incidents studied, which represents a significant management failure. Project management failures were commonly reported, most of which involved inadequate attention to coordinating the work of different trades and to managing subcontractors to ensure that workers on site had the requisite skills to perform the work safely. The next level of contributing causes identified in the HSE model is termed 'Shaping factors' which include issues such as the level of supervision provided, site constraints, housekeeping and the state of workers' health and fatigue (discussed in more detail below). Poor communication within work teams was also identified as an important shaping factor. The most immediate circumstances in the HSE incident causation model are the suitability, usability and condition of tools and materials, the behaviour, motivation and capabilities of individual workers and features of the 


\section{Helen Lingard}

physical site environment, such as layout, lighting and weather conditions. While it is important to identify these immediate circumstances, the model acknowledges that construction incidents occur as a result of a complex process, involving proximal, as well as distal causes 'upstream' of the construction site. This presents a challenge for human resource management, as it requires OHS management activities be implemented across an interorganisational landscape. In the management of OHS, the human resource function cannot be solely internally focused and requires systems and behaviours that support liaison and coordination with a wide range of external organisations with which a construction firm does business.

The HSE model is particularly helpful in the analysis of injuries/incidents in the construction context because it adopts a similar framework to that presented by Reason, but it also reflects the construction industry context. Thus it supports an analysis of human, technological and organisational factors in project procurement and site-specific environments and has considerable potential to direct prevention efforts.

\section{Long bours, fatigue and burnout}

One causal factor in construction safety incidents that has received insufficient attention until recently but is a key feature of contemporary models of injury causation is fatigue. It is widely reported that fatigue results in impaired performance and 'accidents.' (Williamson, Lombardi, Folkard, Stutts, Courtney, Connor, 2011). Given the long work hours and physically demanding nature of construction work, the impact of fatigue on the OHS of construction workers warrants attention.

Construction workers tend to work long hours. For example, in Australia, Lingard and Francis (2004) report that the average number of hours worked each week is 63 among site-based employees in direct construction activity, 56 hours among employees who worked mostly in site offices and 49 among employees in the head office of construction companies. The number of hours worked each week is a significant predictor of worker burnout (Lingard and Francis, 2005). Burnout, itself a form of diminished psychological wellbeing, has also been associated with the experience of distress, anxiety, depression, reduced self-esteem and substance abuse (Maslach, Schaufeli and Leiter, 2001).

Construction workers may be at a greater risk of injury as a result of the hours that they work because long hours are linked to elevated risk of error and injury (Olds and Clarke, 2010). Dembe et al. (2005) report that, for every five hours worked past 40 hours per week, the average risk of injury increases by 0.7 injuries per 100 worker hours. Further, working more than 60 hours increases the risk of injury by 23 per cent (Dembe et al. 2005). Working long hours increases exposure to work hazards, such as noise, chemicals, physical demands, heat and psychological stress (Caruso et al. 2006). In construction these exposures (and their effects) are likely to vary 
by trade. For example, in a comparative analysis of the fatigue and health effects experienced by construction trades, Chang et al. (2009) report that scaffolders have shorter sleeping hours and higher levels of physical pain than other trades. In the same study, concretors, who tended to be older than other worker groups, experienced diminished right-hand grip strength and back strength after a workshift, which the researchers attribute to posture and the vibration effects associated with concreting tasks (Chang et al. 2009). A recent analysis of fatigue experienced by workers at forty construction projects in Queensland, Australia revealed that average weekly work hours and commuting time were significant correlates of fatigue. Fatigue levels were also related to a range of wellbeing indicators including sleep disturbances, headaches, gastro-intestinal problems, respiratory problems, overall physical illness and psychological wellbeing (Hobman et al. 2010). The rate of 'near misses' was significantly greater among workers reporting high fatigue levels.

Long hours also reduce time available for sleep and recovery, which is essential for workers' wellbeing (Sonnentag and Zijlstra, 2006). Research has linked workplace sleepiness with self-reported safety behaviour, such that people who experience high levels of workplace sleepiness report low levels of safety behaviour (DeArmond and Chen, 2009). Workplace sleepiness was also positively linked to the frequency and severity of pain experienced by workers. The link between sleep and safety is evidenced in research by Barnes and Wagner (2009), who report that changes to daylight saving reduces average sleep by 40 minutes per night and is associated with a significant increase in both the frequency and severity of workplace injuries.

Folkard and Lombardi (2006) argue that regulation that restricts the total number of hours worked per week, such as that implemented in Europe under the EU's 'Working Time Directive', may not be the best solution to the problem, because injury risk is not just a function of the number of hours worked per week but the configuration and length of shifts that are worked, as well as the frequency and duration of rest breaks. The length of shifts appears to be a risk factor. Folkard and Lombardi (2006) report that relative to eight-hour shifts, ten-hour shifts are associated with a 13 per cent increased risk of injury and 12 -hour shifts with a 27.5 per cent increased risk of injury. The risk of injury also increases progressively over successive workshifts, although this increase is more dramatic in successive night shifts than successive day shifts. Folkard and Lombardi (2006) report that the risk of injury increases substantially and linearly as the length of time between breaks increases. Thus, frequent breaks can apparently negate some of the effects of shift length.

From a human resource management perspective, there needs to be a better understanding of the implication of work shift design and rostering arrangements for OHS in the construction context. In particular, the question of sufficient rest and recovery within work schedules warrant specific investigation. However, any redesign of work schedules in the 
industry will inevitably involve interaction between $H R$ and other construction management functions, including cost planning, programming and resourcing of construction work.

\section{Workers' bealth and wellbeing}

Hillier et al. (2005) write of an 'endemic un-wellness' that is affecting employees' behaviour within organisations, suggesting that a large number of employees and, by logical inference, organisational cultures are unwell. This is compounded by an ageing workforce. For example, 33 per cent of Australia's 864,100 construction workers is aged between 45 and 70 . Of those, 83 per cent suffer from health conditions classed as national Health Priority Areas, i.e., arthritis or osteoporosis and musculoskeletal conditions, asthma, cancer, cardiovascular disease, diabetes, injury, mental health and obesity (ABS, 2008). This is a concern because the health of a workforce is essential to productivity, performance and efficiency (Miller and Haslam, 2009). While it has long been recognised that workplaces expose workers to physical and chemical hazards, researchers have only recently begun to expose the health impact of long hours and psycho-social stressors. Another recent development has been the blurring of the distinction between occupational and non-occupational health effects (Drennan, Ramsay and Richey, 2006). There is a growing recognition that employee health and wellbeing are influenced by a complex interaction of factors in work and non-work domains.

In several countries, projections of future health care have led policymakers and some large companies to integrate preventive OHS management activities with positive health promotion activities. This integrated approach arguably optimises health outcomes through the simultaneous assessment and reduction of both occupational and lifestyle health risks.

A report published by Pfizer Inc in 2001, titled 'The Health Status of the United States Workforce' provided a summary of US workforce health data. According to the report, on average, employees with hypertension miss 67 per cent more workdays per year than non-hypertensive workers (Peregrin, 2005). Although hypertension is asymptomatic, Peregrin (2005) identifies serious behavioural risk factors associated with this condition, including smoking, sedentary lifestyle and obesity. In the light of this report, in the United States, NIOSH introduced a campaign called 'Steps to a Healthier US Workforce.' Hillier et al. (2005) describe a similar initiative called the 'Healthy Workforce Initiative' in the UK. This initiative was jointly sponsored by the Department of Health and the principal OHS regulatory body (the Health and Safety Executive) thereby bringing workforce health issues into the mainstream OHS arena.

In Australia a national telephone survey of 16,304 Australian workers conducted between 1998 and 2001 revealed that a large proportion of Australian workers rate their health to be sub-optimal (Korda et al. 2002). 
Male, blue-collar workers rated their health particularly poorly compared to other groups. These differences persisted after controlling for confounding variables including age, smoking and employment intensity (Korda et al. 2002). Almost two-thirds of the Australian workers sampled reported a current long-term health condition, such as asthma, arthritis, hayfever, back pain, cardiovascular disease or other long-term health conditions. Regular physical activity has been found to lower the risk of heath-related disease such as cancer (American Institute for Cancer Research, 2007) and positively impact on work-life balance, health and wellbeing. Studies have indicated that construction-based blue-collar workers are less likely to engage in leisure-time physical activity (Burton and Turrell, 2000), which may be due to levels of physical labour associated with work (Sorensen et al. 2009).

\section{Health promotion}

An increasing number of organisations have initiated programmes designed to improve the general physical and mental health of their employees (DeGroot and Kiker 2003). DeGroot and Kiker (2003) distinguish between reactive employee health management programmes and those focused on more positive health promotion. Reactive programmes are those in which assistance is only provided once a particular health problem, for example alcoholism, is identified and help is sought. In contrast, occupational health promotion programmes focus on changing behaviours, at work and outside work, before adverse health outcomes occur. These programmes are becoming more widespread in construction (see below) and are designed to promote behaviours that will improve employees' fitness, health and general wellness. Typical components are:

- the provision of nutritious options in cafeterias and vending machines and/or employer subsidies for the purchase of healthy foods (which are often more expensive than non-healthy foods);

- smoking cessation interventions;

- encouraging exercise by subsidising memberships of fitness centres and by demonstrating management commitment to exercise; and/or

- offering onsite health education and screening for issues like high blood pressure or cholesterol (White 2005).

One interesting and unresolved aspect of health promotion initiatives relates to the extent to which organisations should 'interfere' with workers' lifestyle choices outside of work. This point is particularly contentious in relation to 'fitness for work' programmes that involve drug testing of workers (widely used in the Australian mining sector). In order to justify the implementation of such programmes, employers are required to demonstrate a clear connection between workers' activities out of work hours and their ability to perform their work during work hours. Further, the privacy of workers 


\section{Helen Lingard}

must be very scrupulously safeguarded in the implementation of these programmes. However, in relation to programmes designed to promote more general health and fitness, it is equally important that these programmes be operated in a fair, reasonable and non-discriminatory manner. As in all other aspects of the management of workers' health, safety and wellbeing, the involvement of workers in the design of health programmes is strongly recommended.

\section{Case study 6.1}

\section{West Gate Freeway upgrade, Melbourne, Australia}

The West Gate Freeway upgrade project aimed to eliminate conflicting merging and weaving movements along Melbourne's most heavily trafficked and economically important transport connection by constructing extra collector-distributor lanes in both directions. The freeway was widened by one lane, a new elevated carriageway was constructed and a major interchange was redesigned. The length of the 5.5 kilometre stretch of freeway covered by the project was a mixture of at grade and elevated carriageways and, during construction, work was required to take place adjacent to the existing freeway that remained open, as well as above other roads, railways and tramlines. The requirement to minimise traffic disruption necessitated construction work at night and during weekends. The project was delivered using an innovative alliancing delivery mechanism. Alliance participants included VicReads, Thiess, Baulderstone, Parsons Brinkerhoff and Hyder Engineering.

'Health and Wellbeing' was established as one of the project's Key Result Areas, for which all managers were given responsibility and accountability. Early in the life of the project a Health and Wellbeing Committee was established with responsibility for the development of health and wellbeing strategies and monitoring the project's performance in this important area. During the life of the project, a range of initiatives was implemented. These included the provision of onsite flu vaccinations, cholesterol and blood pressure testing and workstation ergonomic assessments for staff based in the project office. To help workers relax during work breaks, books, puzzles and magazines were provided in lunch rooms and a table tennis table was installed in a designated recreation area onsite. Following a project worker's prostate cancer diagnosis, a special seminar was arranged and delivered by a leading Melbourne medical specialist on this topic. A similar information session was conducted in relation to skin cancer prevention and onsite skin cancer checks were carried out. Activities designed to promote a healthy lifestyle among workers included a 'quit smoking seminar and the provision of onsite advice from a 
dietician. Various initiatives designed to promote physical activity were implemented, including the sponsorship of workers who joined a 'Step Challenge' exercise programme and who entered charity sporting events. The project also funded bicycle repairs and encouraged workers to participate in a 'ride to work' day. To combat issues of work stress and long hours, stress and time management workshops were held.

During November and December 2009, two work-life evaluation workshops were held with workers of the West Gate Freeway upgrade project. The first workshop was held with seven salaried (professionall managerial) workers. The second workshop was held with seven waged (blue collar) workers. The workshops explored the effectiveness of health and wellbeing strategies implemented at the project. The workshops indicated that the health and wellbeing strategies had been positively received by both salaried and waged workers at the project. One participant commented: 1 think they lhe strategies/ cater for everybody because there's a lot of people at our depot that were at the prostate cancer seminar and skin cancer checks and even the bealth checks I beard yesterday was right across the whole board, so it was pretty good'. Participants also commented favourably on the peace of mind that participating in health-checks provided them with. For example, one said I mean with all the health stuff for me it was stuff that I wouldn't have done otherwise. It was just good to do it just for peace of mind'. Another remarked ' $I t^{\prime}$ 's a peace of mind thing, quite a few of those things [strategies], okay you know you re fine, you ve got a few minor problems, but you can get them sorted out if you know what they are. And I think that's good because it takes the worry away, the stress of it and allows you to focus on your work.'

\section{Work stress}

The construction industry is a high risk industry for work stress. In an analysis of stress among construction site managers, Sutherland and Davidson (1989) identify inadequacy of information flow, onerous paperwork and excessive workload as the top three stressors. Leung et al. (2007) also report high levels of objective stress in construction estimators, associated mainly with a perceived lack of autonomy and/or low levels of reward. In a study of Hong Kong construction industry employees, onerous bureaucracy, a lack of opportunity to learn new skills and work-family conflict were ranked the three most difficult stressors to manage ( $\mathrm{Ng}$, Skitmore and Leung, 2005).

Work stress is associated with lower levels of job performance. For example, Djebarni (1996) reports that the relationship between leadership 
and effectiveness is contingent upon levels of stress and provides some evidence for a curvilinear relationship between stress and performance, i.e., performance is low in conditions of low and high stress, but high when stress levels are moderate (the inverted U-curve). However, Leung et al. (2008), report that the task performance of construction project managers is inversely linked to objective stress and found no evidence for a curvilinear relationship. They attribute this to the fact that the objective stress levels of project managers are consistently above the threshold at which the inverted U-curve would apply. More recently, Leung et al. (2010) report emotional stress is positively linked to workers' injury experience in the Hong Kong construction industry. In Australia, Haynes and Love (2004) identified workload, long hours and insufficient time with family as the three most significant stressors experienced by construction project managers. They suggest that the sources of stress have significant implications for the adjustment or coping mechanisms available to project managers, who will have limited access to social support outside the workplace to help them deal with stress. Also in Australia, Love et al. (2010) report that employees of contractors suffer higher levels of stress and lower levels of workplace support than consultants, suggesting that workplace support can help to mitigate the harmful effects of high-stress work. Increasing research evidence supports an ecological model of stress, in which work and non-work environments interact in complex ways to shape the experiences of construction industry workers (see, for e.g. Leung et al. 2008).

Stressful work conditions are serious risk factors for employees' mental health but it is now known that stress is also a risk factor in musculo-skeletal disorders (MSDs). This relationship is strong both in relation to the frequency and duration of MSD claims. For example, stressors or sources of stress play an important role in the development, exacerbation and maintenance of work-related upper extremity disorders (Bongers et al., 2002) and back pain (Linton, 2001). Indeed, Linton (2001) suggests that eliminating stress risk factors could reduce the number of cases of back pain by up to 40 per cent. The pathways by which work stress contribute to MSDs are not fully understood but Bongers et al. (2002) suggest that stressful work conditions: (i) have a direct effect upon the speed of movements, applied force and/or posture; (ii) cause physiological changes leading to MSD problems; (iii) lead to a different appraisal of MSD problems; and (iv) influence the transition from acute to sub-acute to chronic MSD pain.

One form of work stress experienced acutely by construction workers is work-family conflict. Lingard, Francis and Turner (2010) report that Australian construction workers experience higher levels of work-family conflict than those reported by workers in a variety of other industries. A longitudinal study by Jansen, Kant, Amelsvoort, Kristensen, Swaen and Nijhuis (2006) shows a clear correlation between work-family conflict and sickness absence, even after controlling for other issues, such as workers' age and the presence of a long-term disease. Research also reveals that 
work-to-family conflict acts as the mechanism by which adverse work conditions translate into depression (Franche et al. 2006). According to Wang et al. (2007) work-family conflict is significantly associated with mental disorders in the American working population. This association was found for both women and men, although the association was stronger in men aged between 26 and 45 years of age and among married or divorced men with children. The latter finding is pertinent to the predominantly male construction industry. Wang et al. (2007) suggest this might be due to the fact that middle age is a period of high productivity in which many workers also start a family. The combination of pressures to provide financially and participate in family life at this busy time, the researchers suggest, takes its toll on men's mental health. However, there is also evidence that women in construction occupations are also badly affected by work-family conflict Sang et al. (2007) compared the experiences of male and female architects in the United Kingdom and report that female architects experience significantly lower overall job satisfaction and significantly higher levels of work-family conflict and turnover intention than their male counterparts.

Work-family conflict also impacts upon health and wellbeing indirectly, via employees' health-related behaviours. For example, Allen and Armstrong (2006) report that family interference with work is associated with the consumption of more fatty foods and less physical activity, while work interference with family is associated with lower consumption of healthy foods. Research has linked work-to-family conflict and role overload with unhealthy food choice coping strategies, for example eating take-away or fast food rather than home-cooked food, suggesting that this has serious implications for the nutrition and health of working parents and their children (Devine et al. 2006).

There is now a strong body of evidence to suggest that experiences at work can spill over into workers' activities outside of work and, where this 'spillover' is negative the impacts on workers' health can be significantly damaging. As a result of this understanding, organisational OHS programmes are increasingly being broadened to incorporate strategies designed to support workers in achieving a work-life balance.

\section{Managerial influence and safety leadership}

\section{Managerial influence}

Early OHS management approaches focused upon engineering and technological solutions to emerging safety hazards. However, since the midtwentieth century, there has been a growing interest in the impact of management and organisational factors upon OHS performance (Flin 2003). Early examples of this approach were investigations by Simonds and Shafai-Sahrai (1977) and Smith et al. (1978). The attention given to management and organisational factors has become so significant that Hale 
and Hovden (1998) have referred to it as the 'third age of safety.' Various management actions have been observed in organisations demonstrating good OHS performance. These include:

1 Management commitment to OHS. Early studies revealed that workers' perceptions of managers' commitment to OHS were a major factor in the success of an organisation's OHS programme (Zohar 1980). Management commitment has been referred to as a necessary condition for a safe workplace (Shannon et al. 2001).

2 Worker participation in the OHS process. Workers are recognised to be in the best position to make suggestions about OHS improvements and teams have been found to make better OHS decisions than individuals (Culvenor 2003). The encouragement of upward communication and involvement in decision-making also has an empowering effect, providing employees with authority, responsibility and accountability (Vassie and Lucas, 2001). However, while encouraging worker involvement, managers must also take care not to abrogate their managerial responsibility for OHS (Roy, 2003).

3 Provision of OHS training. In order to actively participate in the OHS process, it is critical that workers are provided with adequate OHS training. OHS training programmes should be carefully designed after a comprehensive assessment of the organisation's needs, i.e. what OHS knowledge, skills and abilities are missing that are required to enable employees at all levels to perform their jobs safely?

4 Hiring practices. Where organisations establish recruitment criteria that are designed to ensure the selection of people who are safety conscious, organisational OHS performance is reported to be better. Also, when the organisation actively strives to communicate organisational OHS values and commitment to prospective workers, it is more likely to recruit workers with compatible OHS attitudes and expectations.

5 Reward systems. Incentive programmes that reinforce desired OHS behaviours are a feature of organisations with good OHS performance. Vredenburgh (2002) suggests that rewards can include informational (e.g. feedback), social (e.g. praise/recognition) and tangible (e.g. bonuses/ awards) reinforcement for OHS perfromance.

6 Communication and feedback. Clear and consistent communication of OHS expectations is vital to OHS performance. The provision of constant feedback to workers about their OHS performance is also critical because many serious OHS incidents occur as a result of actions that are routinely undertaken but which, in most instances, do not result in injury.

One striking feature of research into managerial and organisational determinants of OHS performance is the consistency with which these management actions have been linked to high levels of OHS performance 
(Varonen and Mattila 2000). This consistency demonstrates that managers' actions are an extremely important factor in determining an organisation's OHS performance.

Researchers have examined the role played by different levels of management in shaping OHS performance and, consequently, there is a growing understanding of the need to pay attention to managerial actions at all levels within the organisation. Senior managers play a key role in establishing an organisation's OHS policy, setting strategic objectives for OHS and allocating organisational resources to the overall management of OHS. It is critical that managers at this level are seen to take OHS seriously, demonstrating their commitment to OHS through their actions. However, workers 'at the coalface' are likely to have little direct contact with senior management and the role played by middle managers and first level supervisory personnel is equally critical. Where middle managers or supervisors do not behave in a manner which is consistent with espoused organisational OHS policy or value statements, these policies and values are unlikely to be put into practice.

The influence of supervisors on safety performance is likely to be increased in the construction context because construction work is highly decentralised, with productive work undertaken at sites remote from the corporate office. This geographical dispersion is likely to increase the behavioural influence of supervisors relative to senior management. Construction work is also largely non-routine, necessitating the exercise of supervisory discretion in the interpretation of formal safety policies and procedures. In this context, the role of supervisors in shaping subordinates' safety behaviour is likely to be considerably greater than in stable work contexts characterised by routine production processes. The importance of first-level supervisors in the construction context is illustrated in the Case Study below.

\section{Case Study 6.2}

\section{Supervisory safety leadership in the construction industry}

A research project was undertaken to investigate the extent to which supervisors influence the injury rates of the workgroups they supervise in the Australian construction industry. Data was collected within three organisations as follows:

Study one $(\mathrm{n}=71)$ was undertaken within the regional construction and maintenance works district of a state-based road construetion and maintenance organisation in the south east of Australia;

Study two $(\mathrm{n}=99)$ was undertaken at a hospital construction project in Melbourne; and 
Study three ( $\mathrm{n}=137$ ) was undertaken at the Melbourne operations of a national steel reinforcement manufacturing organisation.

Data was collected using a survey tool specially developed to measure workers' perceptions of their immediate supervisors' safety response, using a survey instrument developed by Zohar (2000). Supervisors' safety response is understood to be a facet of group-level safety climate, which is linked to the safety performance of workgroups in nonconstruction settings (Zohar, 2000). The research also measured workers' perceptions of the organisation-level safety climate, 1.e., the 'shared perceptions of the organisation's practices and policies relating to safety' (Kath et al. 2010, p. 1489).

Data was analysed to test whether supervisors's safety response mediated the relationship between perceptions of the organisational safety climate and the workgroup injury frequency rates within the three organisations. Analysis of the data confirmed that the relationship between perceptions of the organisational safety climate and workgroup injury frequency rate were fully mediated by perceptions of supervisors' safety response. Thus, workers' perceptions of organisational policies and practices relating to safety impact upon OHS performance indirectly, through supervisors' safety responses. The results highlight the critical role played by first-level supervisors in communicating to workers 'what the organisation really wants' in relation to OHS. This suggests a 'cascading' managerial influence by which management commitment to safety filters down through organisational hierarchies. Supervisors act as a 'conduit' through which organisational safety priorities are communicated and provide important feedback to front-line workers concerning the appropriateness of their behaviour (Lingard et al. 2009).

The research also sought to examine the mechanisms of influence among subcontracted workgroups at the hospital construction project. Workers' perceptions of the safety policy and practices of the principal contractor positively and significantly predicted subcontracted workers' perceptions of their own organisations' safety policy and practices. Thus, when subcontracted workers perceived the principal contractor was serious about OHS, they were more likely to perceive that their direct employer (i.e., the subcontractor who employs them organisation) is similarly committed to OHS.

First-level supervisors (foremen and leading hands) played a critical role in shaping workgroup safety performance. Perceptions of the subcontractor supervisors' safety response were inversely related to subcontracted workgroup's injury rate. It is through supervisors thatthe behavioural benefits of organisational safety policies and practices are realised. When supervisors establish high expectations 
for safety, are consistent in their actions and engage in frequent safetyrelated interactionis with workers, safety performance is likely to be enhanced.

The research highlights the role played by supervisors as a critical conduit through which organisation's safety values and priorities are communicated to workers. Supervisory personnel are particularly influential because they 'filter' organisational OHS messages and shape employees' beliefs about the importance of OHS relative to other organisational goals, e.g. production and cost.

Several researchers have tried to modify supervisors' safety leadership behaviour to improve workgroup OHS performance (Zohar, 2002). More recently, Kines et al. (2010) examined supervisors' interactions with workers in the Danish construction industry. They evaluated a 'safety coaching' intervention in which supervisors (foremen) were encouraged to discuss safety with workers and provide proactive and supportive feedback about safe ways of working.

Baseline measurements revealed that foremen spoke with their workers several times a day but that safety was only mentioned in between 6 and 16 per cent of these verbal exchanges.

Supervisors who were coached and given bi-weekly feedback increased the safety content of their interactions with workers, relative to supervisors who received no coaching or feedback. Also, the levels of safety observed in workgroups whose supervisors received coaching and feedback improved significantly over baseline conditions. This suggests that the OHS performance of workers can be positively influenced by interventions designed to improve the safety management practices of first-level supervisors in the construction industry.

\section{Trust and worker involvement}

Recent research has focused on the social context of work and the role played by trust and mutual understanding, particularly between occupants of different levels within organisational hierarchies, in influencing OHS outcomes (Clarke, 2006). Conchie and Donald define trust as 'an individual's willingness to rely on another (i.e. a leader) based upon positive expectations that he or she will act safely or intend to act safely' (p. 137). Kath et al. (2010) present evidence indicating that a consistent approach to the application of organisational safety policies and practices demonstrates a concern for workers' health and safety and helps to establish trust. In an analysis of safety leadership in the UK construction industry, Conchie and Donald (2009) reveal that the positive impact of transformational safety leadership is contingent upon the extent to which workers perceive their supervisors as trustworthy in relation to OHS. In conditions of low trust, transformational leadership has no significant impact upon workers' safety 
citizenship behaviour. McLain and Jarrell (2007) suggest that trust encourages the sharing and acceptance of safety information, which increases knowledge about how to integrate task and safety demands and reduces uncertainty about what is expected. Where workers trust managers' handling of OHS, they are more likely to believe that safety and production targets are compatible (McLain and Jarrell, 2007). Luria (2010) found that trust between leaders and subordinates was directly linked to reduced injury rates within workgroups. Thus it seems that high-trust relationships between supervisors and workers create a safer work environment. Also, over time, workers who perceive that their supervisors place importance upon OHS will develop strong and positive work group safety climates, i.e. a perception that safety is a priority for their workgroup. Not only does trust seem to be an important determinant of safety within organisations but research shows that it is also a predictor of effective rehabilitation and return-to-work of injured workers (Baril et al. 2003).

Given the importance of trust to workers' health, safety and wellbeing, there may be a need to re-think traditional management approaches to OHS. Traditionally OHS management has assumed workers are motivated to exert only enough effort as is necessary for task completion. Management approaches to OHS have been based upon rules to enforce behaviour and relied upon managers' use of legitimate authority to control workers' behaviour (Zacharatos et al. 2005). Zacharatos et al. (2005) suggest that workers' commitment to achieving organisational goals can be enhanced by encouraging participative decision-making, treating workers with respect, sharing information and providing high-quality training. This shift from a 'control-based' to a 'social exchange' approach to the management of OHS hinges upon the workers' belief in the trustworthiness of management with regard to workers' OHS. Trust is enhanced in situations in which there is open communication between workers and managers and workers' suggestions for safety improvements are sought and taken seriously. Törner and Poussette (2009) report that Swedish construction organisations with high safety standards adopt joint problem-solving and involve workers and their representatives in OHS decision-making. Worker participation in the development and implementation of organisational OHS initiatives can facilitate the identification of practical and sustainable solutions that are more likely to yield long-term OHS improvements (Rasmussen et al. 2006).

\section{Conclusions}

Workers' health, safety and wellbeing are critical to the construction industry's sustainability and long-term economic performance. Yet the industry faces many difficult challenges. The International Labour Organization (ILO) estimated at least 60,000 fatal accidents occur each year on construction sites around the world - representing one in six of all fatal work-related accidents (ILO, 2005). In developed economies the construction 
industry is characterised by an intransigent residual level of workers' death, injury and illness that seems resistant to change. In developing countries, the situation is much worse. For example, according to Wells and Hawkins (no date) there are, on average, 100 fatalities on UK construction sites each year. However, the ILO estimated the number of deaths from accidents at work in India in 2001 to be 40,000 , with an additional 262,000 workers dying from work-related diseases and 65,000 from dangerous substances. Assuming that construction accounts for one sixth of these deaths, then over 60,000 Indian workers died as a result of work exposure in a single year (Wells and Hawkins, no date).

It is often argued that 'safety saves money' and therefore there is a natural cost incentive for organisations to invest in OHS. Although the aggregated costs of work death, injury and illness are very substantial, Australian data suggests that the largest proportion of these costs is borne by the community (e.g. in social security and welfare payments) or by injured workers and their families (e.g. in the provision of care for injured or ill persons). The proportion of costs of work-related death injury and illness borne by employers is relatively small. Further, this is only one side of the OHS equation. In order to determine whether there is a cost incentive for construction firms to prevent deaths, injuries and illnesses, it is necessary to compare the costs of harm with the costs of prevention. At the level of a single enterprise, e.g. a construction firm, profitability is usually measured on an annual basis. Given this accounting practice, it is unlikely that the return on investment in a period of one year would be sufficient to justify significant investment in preventive measures, particularly in the case of high severity but low frequency events.

Given that this is the case, the regulation of OHS and other aspects impacting workers' wellbeing, such as work hours, remains critical and governments have an important role to play in ensuring that minimum standards are maintained.

Ensuring equity and protecting the health, safety and wellbeing of vulnerable worker groups is a growing challenge. There is considerable evidence that young workers, migrant workers and workers whose employment arrangements are precarious are high risk groups for workrelated harm. Further, it is these groups who may find it difficult to engage in organised labour activities, participate in worker-employer consultative processes and access the support and advice they need to equip them to advocate for improvements in work conditions.

Long work hours and fatigue remain a problem for construction workers' health, safety and wellbeing. The problems associated with long hours and fatigue are experienced by both blue and white collar workers, and are particularly acute in project-based work. In the author's research on one large construction project in Melbourne, a managerial employee explained the issue of burnout related to long hours as follows: 
We burn a lot of people out who would otherwise stay in the industry. I've seen projects where we've had engineers covering two shifts working 16 hours and they've got an hour drive to and from work and they end up having six hours at home and they do that for nine months and they give it away, not only the project away, they give the industry away and we just burn them out

It is essential that construction organisations consider the impact of work schedules on workers' health, safety and wellbeing and ensure that sufficient opportunities for rest and recovery are provided to mitigate some of these problems.

Much work has been done in the analysis of causes of work-related injury and we now have robust models to explain how injuries occur. It is fair to say that, in general, we know what causes work-injuries and by logical extension, we know what needs to be addressed to prevent similar injury events from happening in the future. There is also a growing understanding of the importance of the social context of work and we are developing a good understanding of the importance of safety leadership and trust between workers and managers in ensuring a safe and healthy work environment. It is likely that to achieve sustainable improvements in OHS in the construction industry, organisations will need to move away from the traditional controlbased approach to managing human resources and adopt the more participatory, high-involvement approach. Unfortunately, this type of change will not be easy to implement and would necessarily challenge prevailing neo-liberal concepts of managerial prerogative.

\section{References}

Allen, T. D. and Armstrong, J. (2006) Further examination of the link between work-family conflict and physical health: The role of health-related behaviours, American Behavioral Scientist, 49, 1204-21.

American Institute for Cancer Research (2007) Food, Nutrition and the Prevention of Cancer: A Global Perspective, Washington DC, American Institute for Cancer Research.

Arditi, D. and Chotibhongs, R. (2005) Issues in subcontracting practice, Journal of Construction Engineering and Management, 131, 866-76.

Australian Bureau of Statistics, (2008) 4837.0.55.001, Health of Mature Age Workers in Australia: A Snapshot, 2004-0.5, Canberra.

Baril, R., Clarke, J., Friesen, M., Stock, S., Cole, D. the Work Ready Group (2003) Management of return-to-work programs for workers with musculoskeletal disorders: a qualitative study in three Canadian provinces, Social Science and Medicine, 57, 2101-14.

Barnes, C. M. and Wagner, D. T. (2009) Changing to daylight saving time cuts into sleep and increases workplace injuries, Journal of Applied Psychology, 94, 1305-17. 
Bluff, E. and Gunningham, N. (2003) Principle, Process, Performance or What? New Approaches to OHS Standards Setting, Working Paper 9, National Research Centre for Occupational Health and Safety Regulation, Australian National University, Canberra, online at www.ohs.anu.edu.au.

Bongers, P. M., Kremer, A. M. and ter Laak, J., (2002) Are psychosocial factors, risk factors for symptoms and signs of the shoulder, elbow, or hand/wrist?: A review of the epidemiological literature, American Journal of Industrial Medicine, 41, 315-342.

Breslin, F. C., Polzer, J., MacEachen, E., Morrongiello, B. and Shannon, H. (2007) Workplace injury or 'part of the job'?: Towards a gendered understanding of injuries and complaints among young workers, Social Science and Medicine, 64, 782-93.

Burt, C. D. B., Chmiel, N. and Hayes, P. (2009) Implications of turnover and trust for safety attitudes and behaviour in work teams, Safety Science, 47, 1002-06.

Bust, P. D., Gibb, A. G. F. and Pink, S. (2008) Managing construction health and safety: Migrant workers and communicating safety messages, Safety Science, 46, $585-602$.

Caruso, C. C., Bushnell, T., Eggerth, D., Heitmann, A., Kojola, B., Newman, K., Rosa, R. R., Sauter, S. L. and Vila, B. (2006) Long working hours, safety and health: Toward a national research agenda, American Journal of Industrial Medicine, 49, 930-42.

Chang, F-L., Sun, Y-M., Chuang, K-H. and Hseu, D-J. (2009) Work fatigue and physiological symptoms in different occupations of high-elevation construction work, Applied Ergonomics, 40, 591-6.

Chin, P., DeLuca, C., Potyh, C., Chadwick, I., Hutchinson, N. and Munby, H. (2010) Enabling youth to advocate for workplace safety, Safety Science, 48, $570-9$.

Clarke, S., (1999) Perceptions of organizational safety: implications for the development of safety culture, Journal of Organizational Behavior, 20, 185-98.

Conchie, S. M. and Donald, I. J., (2009) The moderating role of safety-specific trust on the relation between safety-specific leadership and safety citizenship behaviors, Journal of Occupational Health Psychology, 14, 137-47.

Culvenor, J. (2003) Comparison of team and individual judgments of solutions to safety problems, Safety Science, 41, 543-56.

Dawson, S., Willman, P., Clinton, A, and Bamford, M. (1988) Safety at Work: The limits of self-regulation, Cambridge University Press, Cambridge.

DeGroot, T. and Kiker, D. S. (2003) A meta-analysis of the non-monetary effects of employee health management programmes, Human Resource Management, 42, 53-69.

Dembe, A. E., Erickson, J. B., Delbos, R. G. and Banks, S. M. (2005) The impact of overtime and long work hours on occupational injuries and illnesses: New evidence from the United States, Occupational and Environmental Medicine, 62, 588-97.

Devine, C. M., Jastran, M., Jabs, J., Wethington, E., Farell, T. J. and Bisogni, C. A. (2006), A lot of sacrifices: Work-family spillover and the food choice coping strategies of low-wage employed parents, Social Science and Medicine, 63, 591-603.

Djebarni, R. (1996) The impact of stress in site management effectiveness, Construction Management and Economics, 14, 281-93. 
Dong, X. S., Fujimoto, A., Ringen, K. and Men, Y. (2009) Fatal falls among Hispanic construction workers, Accident Analysis and Prevention, 41, 1047-52.

Drennan, F. S., Ramsay J. D. and Richey, D. (2006) Integrating employee safety and fitness: A model for meeting NIOSH's Steps to a Healthier US Workforce challenge, Professional Safety, 51, 26-35.

Driscoll, T. (2006) Fatal injury of young workers in Australia, Journal of Occupational Health and Safety: Australia and New Zealand, 22, 151-61.

Emberland, J. S. and Rundmo, T. (2010) Implications of job insecurity perceptions and job insecurity responses for psychological wellbeing, turnover intentions and reported risk behaviour, Safety Science, 48, 452-9.

Fabiano, B., Currò, F., Reverberi, A. P. and Pastorino, R. (2008) A statistical study on temporary work and occupational accidents: Specific risk factors and risk management strategies, Safety Science, 46, 535-44.

Flin, R., (2003) 'Danger - men at work': Management influence on safety, Human Factors and Ergonomics in Manufacturing, 13, 261-8.

Folkard, S. and Lombardi, D. A., (2006) Modeling the impact of components of long work hours on injuries and 'accidents', American Journal of Industrial Medicine, 49, 953-63.

Franche, R. L., Williams, A., Ibrahim, S., Grace, S. L., Mustard, C., Minore, B. and Stewart, D. E. (2006). Path analysis of work conditions and work-family spillover as modifiable workplace factors associated with depressive symptomatology, Stress and Health, 22, 91-103.

Gallagher, C., Underhill, E and Rimmer, M. (2003) Occupational safety and health management systems in Australia: barriers to success, Policy and Practice in Health and Safety, 2, 67-81.

Government of South Australia, (2009) South Australian Construction Industry Workforce Action Plan (2009 - 2014), Adelaide.

Greenwood, M. R. (2002) Ethics and HRM: A review and conceptual analysis, Journal of Business Ethics, 36, 261-78.

Guadalupe, M. (2003) The hidden costs of fixed term contracts: the impact on work accidents, Labour Economics, 10, 339-57.

Guberon, E. and Usel, M. (1998) Permanent work incapacity, mortality and survival without incapacity among occupations and social classes: a cohort study of aging men in Geneva, International Journal of Epidemiology, 27, 1026-32.

Hale, A. R. and Hovden, J. (1998) Management and culture: The third age of safety. A review of approaches to organizational aspects of safety, health and environment, A. M. Feyer and Williamson A. (eds), Occupational Injury: Risk prevention and intervention, 129-65, Taylor \& Francis, London.

Haslam, R. A., Hide, S. A., Gibb, A. G. F., Gyi, D. E., Pavitt, T., Atkinson, S. and Duff, A. R. (2005) Contributing factors in construction accidents, Applied ergonomics, 6, 401-415.

Haynes, N. S. and Love, P. E. D. (2004) Psychological adjustment and coping among construction project managers, Construction Management and Economics, 22, $129-40$.

Heinrich H. W. (1959) Industrial accident prevention (4th edn). McGraw-Hill: New York.

Hillier, D., Fewell, F., Cann, W. and Shephard, V. (2005) Wellness at work: Enhancing the quality of our working lives, International Review of Psychiatry, $17,419-31$. 
Hobman, E. V., Jimmieson, N. L. and McDonald, K. (2010) An Examination of Fatigue in the Construction Industry, The Centre for Organizational Psychology, University of Queensland, Brisbane, February 2010.

Hopkins, A. (1999) For whom does safety pay? The case of major accidents, Safety Science, 32, 143-53.

HSE (Health and Safety Executive) (2003) Causal Factors in Construction Accidents, Research Report 156, HMSO Books, Norwich.

International Labour Organization, (2005) Estimate by ILO on the occasion of the World Day for Safety and health at Work, 2005 www.ilo.org/global/About_the_ ILO/Media_and_public_ information/Press_releases/lang-en/WCMS_ 005161/ index.htm.

Jamal, M. (2004) Burnout, stress and health of employees on non-standard work schedules: a study of Canadian workers, Stress and Health, 20, 113-19.

Janicak, C. A. (2008) Occupational fatalities due to electrocutions in the construction industry, Journal of Safety Research, 39, 617-21.

Jansen, N. W. H, Kant, I. J., von Amelsvoort, L. G. P. M., Kristensen, T. S., Swaen, G. M. H., and Nijhuis, F. J. N. (2006) Work-family conflict as a risk factor for sickness absence, Occupational and environmental medicine, 63, 488-494.

Kath, L. M., Magley, V. J. and Marmet, M. (2010) The role of organizational trust in safety climate's influence on organisational outcomes, Accident Analysis and Prevention, 42, 1488-97.

Katsakiori, P., Sakellaropoulos, G. and Manaatakis, E. (2009) Towards and evaluation of accident investigation methods in terms of their alignment with accident causation models, Safety Science, 47, 1007-15.

Kines, P., Anderson, L. P. S., Spangenberg, S., Mikkelsen, K. L., Dyreborg, J. and Zohar, D. (2010) Improving construction site safety through leader-based verbal safety communication, Journal of Safety Research, 41, 399-406.

Korda, R. J., Strazdins, L., Broom, D. H. and Lim, L., L-Y. (2002) The health of the Australian workforce: 1998-2001, Australian and New Zealand Journal of Public Health, 26, 325-31.

Larsson, T. and Field, B. (2002) The distribution of occupational risks in the Victorian construction industry, Safety Science, 40, 439-56.

Lavack, A. M., Magnuson, S. L., Deshpande, S., Basil, D. Z., Basil, M. D. and Mintz, J. H. (2008) Enhancing occupational health and safety in young workers: the role of social marketing, International Journal of Nonprofit and Voluntary Sector Marketing, 13, 193-204.

Leung, M-Y., Chan, Y. S. and Olomolaiye, P. (2008) Impact of stress on the performance of construction project managers, ASCE Journal of Construction Engineering and Management, 134, 644-52.

Leung, M-Y., Chan, Y. S. and Yuen, K. W. (2010) Impacts of stressors and stress on the injury incidents of construction workers in Hong Kong, ASCE Journal of Construction Engineering and Management, 136, 1093-103.

Leung, M-Y., Chan, Y. S. and Yu, J. (2008) Integrated model for the stressors and stresses of construction project managers in Hong Kong, ASCE Journal of Construction Engineering and Management, 134, 126-34.

Leung, M-Y., Skitmore, M. and Chan, Y. S. (2007) Subjective and objective stress in construction cost estimation, Construction Management and Economics, 25, $1063-75$. 
Lingard, H. and Francis, V. (2004) A comparative study of the work-life experiences of men and women working in office and site-based roles in the Australian construction industry, Construction Management and Economics, 22, 991-1002.

Lingard, H. and Francis, V. (2005) Does work-family conflict mediate the relationship between job schedule demands and burnout in male construction professionals and managers?, Construction Management and Economics, 23, $733-45$.

Lingard, H., Cooke, T. and Blismas, N. (2009) Group-level safety climate in the Australian construction industry: Within-group homogeneity and between-group differences in road construction and maintenance, Construction Management and Economics, 27, 419-32.

Lingard, H., Cooke, T. and Blismas, N. (2010) Safety climate in conditions of construction subcontracting: A multi-level analysis, Construction Management and Economics, 28, 313-825.

Linton, S. J., (2001) Occupational psychological factors increase the risk for back pain: A Systematic Review, Journal of Occupational Rebabilitation, 11, 5-66.

Loosemore, M. and Andonakis, N. (2007) Barriers to implementing OHS reforms - The experiences of small subcontractors in the Australian Construction Industry, International Journal of Project Management, 25, 579-88.

Loughlin, C. and Frone, M. R. (2004) Young workers' occupational safety, The Psychology of Workplace Safety, Barling, J. and Frone M. (eds), American Psychological Association: Washington DC, 107-25.

Love, P. E. D., Edwards, D. J. and Irani, Z. (2010) Work stress, support, and mental health in construction, ASCE Journal of Construction Engineering and Management, 136, 650-58.

Lundberg, J., Rollenhagen, C. and Hollnagel, E. (2009) What-you-look-for-is-whatyou-find - The consequences of underlying accident causation models in eight accident investigation manuals, Safety Science, 47, 1297-311.

Luria, G. (2010) The social aspects of safety management: Trust and safety climate, Accident Analysis and Prevention, 42, 1288-95.

McLain, D. L. and Jarrell, K. A., (2007) Perceived compatibility of safety and production expectations in hazardous occupations, Journal of Safety Research, 38, 299-309.

Manu, P., Ankrah, N., Proverbs, D. and Suresh, S. (2010) An approach for determining the extent of contribution of construction project features to accident causation, Safety Science, 48, 667-92.

Maslach, C., Schaufeli, W. B. and Leiter, M. P. (2001) Job burnout, Annual Review of Psychology, 52, 397-422.

Mayhew, C., Quinlan, M. and Ferris, R. (1997) The effects of subcontracting/ outsourcing on occupational health and safety: Survey evidence from four Australian industries, Safety Science, 25, 163-78.

Miller, P. and Haslam, C. (2009) Why employers spend money on employee health: Interviews with occupational health and safety professionals from British Industry, Safety Science, 47, 163-9.

National Occupational Health and Safety Commission (2004) The costs of workrelated injury and illness for Australian employers, workers and the community, Commonwealth Government of Australia, Canberra. 
Ng, T. S., Skitmore, M. R. and Leung, T. K. C. (2005) Manageability of stress among construction project participants, Engineering, Construction and Architectural Management, 12, 264-82.

Nichols, T. (1997) The Sociology of Industrial Injury, Mansell Publishing, London.

Olds, D. M. and Clarke, S. P. (2010) The effect of work hours on adverse events and errors in health care, Journal of Safety Research, 41, 153-62.

Peregrin, T. (2005) Weighing in on corporate wellness programs and their impact on obesity, Joumal of the American Dietetic Association, 1192-4.

Quinlan, M. (2007) Organizational restructuring/downsizing, OHS regulation and worker health and wellbeing, International Journal of Law and Psychiatry, 30, 385-99.

Rasmussen, K., Glasscock, D. J., Hansen, O. N., Carstensen, O., Jepsen, J. F. and Nielsen, K. J. (2006) Worker participation in change processes in a Danish industrial setting, American Journal of Industrial Medicine, 49, 767-79.

Rowan, J. J. (2000) The moral foundation of employee rights, Journal of Business Ethics, 25, 355-61.

Roy, M., (2003) Self-directed workteams and safety: a winning combination? Safety Science, 41, 359-76.

Sang, K. J. C., Dainty, A. R. J. and Ison, S. G. (2007) Gender: a risk factor for occupational stress in the architectural profession?, Consiruction Management and Economics, 25, 1305-17.

Simonds, R. H. and Shafai-Sahrai, Y. (1977) Factors apparently affecting injury frequency in eleven matched pairs of companies, Journal of Safety Research, 9 , $120-27$.

Smith, J. J., Cohen, H. H., Cohen, A. and Cleveland, R. (1978) Characteristics of successful safety programs, Journal of Safety Research, 10, 5-15.

Sonnentag, S. and Zijlstra, F. R. H. (2006) Job characteristics and off-job activities as predictors of need for recovery, wellbeing and fatigue, Journal of Applied Psychology, 91, 330-50.

Sorensen, G., Sembajwe, G., Harley, A. and Quintiliani, L. (2009) Work and occupation: Important indicators of socioeconomic position and life experiences influencing cancer disparities, Koh, H. K. (ed), Toward the Elimination of Cancer Disparities, Springer, New York, 83-105.

Suraji, A., Duff, A. R. and Peckitt, S. J. (2001) Development of causal model of construction accident causation, Journal of Construction Engineering and Management, 127, 337-44.

Sutherland, V. J. and Davidson, M. J. (1989) Stress among construction site managers: a preliminary study, Stress Medicine, 5, 221-35.

Törner, M. and Poussette, A., (2009) Safety in construction - a comprehensive description of the characteristics of high safety standards in construction work, from the combined perspective of supervisors and experienced workers, Journal of Safety Research, 40, 399-409.

Trajkovski, S. and Loosemore, M. (2006) Safety implications of low-English proficiency among migrant construction site operative, International Journal of Project Management, 24, 446-52.

Tucker, S., Chmiel, N., Turner, N., Hershcovis, M. S. and Stride, C. B. (2008) Perceived organizational support for safety and employee safety voice: The mediating role of co-worker support for safety, Journal of Occupational Health Psychology, 13, 319-30. 


\section{Helen Lingard}

Vassie, L. H. and Lucas, W. R. (2001) An assessment of health and safety management within working groups in the UK manufacturing sector, Journal of Safety Research, 32, 479-90.

Vredenburgh, A. G. (2002) Organizational safety: Which management practices are most effective in reducing employee injury rates, Journal of Safety Research, 33, $259-76$.

Wang, J. L., Affi, T. O., Cox, B. and Sareen, J. (2007). Work-family conflict and mental disorders in the United States: Cross-sectional findings from the National Comorbidity Survey, American Journal of Industrial Medicine, 50, 143-9.

Wells, J. and Hawkins, J. (no date) Promoting Construction Health and Safety through Procurement: A briefing note for developing countries, Institution of Civil Engineers, London, www.engineersagainstpoverty.org/_db/documents/ EAP-ICE_HS_Briefing_Note.pdf.

Williams, Q. Jr., Ochsner, M., Marshall, E., Kimmel, E. and Martino, C. (2010) The impact of a peer-led participatory health and safety training program for Latino day laborers in construction, Journal of Safety Research, 41, 253-61.

Williamson, A., Lombardi, D. A., Folkard, S., Stutts, J., Courtney, T. K. and Connor, J. L. (2011) 'The link between fatigue and safety, Accident Analysis and Prevention, $43,498-515$.

Zacharatos, A., Barling, J. and Iverson, R. D., (2005) High-performance work systems and occupational safety, Journal of Applied Psychology, 90, 77-93.

Zohar, D. (2000) A group-level model of safety climate: testing the effect of group climate on micro-accidents in manufacturing jobs, Journal of Applied Psychology, $85,587-96$.

Zohar, D. (2002) Modifying supervisory practices to improve subunit safety: a leadership-based intervention model, Journal of Applied Psychology, 87, 156-63. 